\title{
PENERAPAN METODE RELIABILITY CENTERED MAINTENANCE (RCM) PADA PERAWATAN MESIN CONVEYOR UNLOADING PHOSPHATE ROCK (Studi Kasus PT PETROKIMIA GRESIK)
}

\author{
Indra Ikhsan Praja ${ }^{1}$, Said Salim Dahda ${ }^{2}$, Dzakiyah Widyaningrum ${ }^{3}$ \\ ${ }^{1}$ Mahasiswa Teknik Industri, Fakultas Teknik, Universitas Muhammadiyah Gresik \\ ${ }^{2,3}$ Dosen Teknik Industri, Fakultas Teknik, Universitas Muhammadiyah Gresik Jl. Sumatera No. 101 \\ GKB-Gresik 61121, Jawa Timur, Indonesia \\ E-mail:djthara.indra@gmail.com
}

\begin{abstract}
ABSTRAK
Proses bongkar material bahan baku pupuk merupakan proses yang penting dalam operasional PT Petrokimia Gresik. Dalam proses distribusi atau pengangkutan raw material dari pelabuhan menuju gudang pabrik atau ruang produksi, salah satu peralatan utama yang digunakan adalah conveyor. Selama ini, conveyor 02M603 yang digunakan dalam proses bongkar di pelabuhan PT Petrokimia masih sering mengalami kerusakan sehingga menimbulkan kerugian salah satunya dalam bentuk biaya demurrage. Solusi dari permasalahan ini ialah memberikan usulan rencana jadwal perawatan mesin dengan menggunakan metode reliability centered maintenance. Hasil penerapan metode Reliability Centered maintenance diperoleh empat komponen yang harus dirawat secara terjadwal (time directed) yaitu: carrier roller, support carrier, impact roller dan rubber seal. Komponen-komponen tersebut merupakan komponen yang paling sering mengalami kerusakan dan menyebabkan downtime pada conveyor 02M603. Berdasarkan hasil analisis diusulkan agar perawatan dilakukan bukan selama 100 jam atau setiap 1 kali bongkar karena salah satu komponen, yaitu carrier roller memiliki nilai MTTF dibawah 200 jam, sehingga apabila perawatan dilaksanakan tiap 200 jam dapat memperbesar kemungkinan terjadinya downtime akibat kerusakan carrier roller.
\end{abstract}

Kata kunci: Perawatan, Reliability Centered maintenance

\section{PENDAHULUAN}

Di PT Petrokimia Gresik, dalam proses distribusi atau pengangkutan raw material dari pelabuhan menuju gudang pabrik atau ruang produksi, salah satu peralatan utama yang digunakan adalah conveyor. Conveyor penting karena bahan baku yang dipindahkan dari pelabuhan ke pabrik tersebut umumnya merupakan bulk material, yaitu bahan material yang dalam pemindahannya tidak memerlukan bag, barrel, bottle, drum dan lain-lain. Adapun bulk material yang ditransfer di PT Petrokimia Gresik antara lain adalah sulphur (belerang) dan phosphate rock (pospat). Adanya kerusakan atau hambatan yang terjadi dapat memberikan dampak besar bagi kegiatan distribusi, salah satunya adalah timbulnya demurrage. Selama ini, karena

keterlambatan waktu bongkar bahan baku dari kapal, PT. Petrokimia Gresik seringkali masih harus mengeluarkan biaya demurrage tersebut, yang jumlahnya mencapai 20.000 USD per hari.

Berdasarkan data yang diperoleh dari perusahaan diketahui bahwa jumlah biaya demurrage yang terbesar adalah pada kegiatan bongkar phospate rock Mesir, yang jumlahnya hampir mencapai $50 \%$ dari total biaya demurrage yang harus dikeluarkan (Weekly
Report Departemen Pengelolaan Pelabuhan Petrokimia Gresik, 2017). Berdasarkan hasil studi awal diketahui pula bahwa penyebab paling dominan dari terjadinya demurrage tersebut adalah internal equipment breakdown pada jalur conveyor 02M603 yang mengalami overload (EVABB Phospate Rock Mesir Bagian Administrasi Pelabuhan Petrokimia Gresik, 2018).

Berdasarkan gambaran kondisi di atas, terlihat betapa pentingnya conveyor dalam proses distribusi/pengangkutan bulk material di PT Petrokima Gresik. Oleh karenanya peralatan tersebut harus dirawat agar bekerja dengan baik, tidak rusak, dan optimal, sehingga perlu dilakukan perawatan secara continuous. Perawatan yang dilakukan di perusahaan selama ini lebih sering dilakukan setelah terjadi kerusakan. Sistem perawatan tersebut kurang optimal dalam memberikan data yang akurat tentang kapan suatu mesin atau komponen akan mengalami kerusakan. Kerusakan yang terjadi pada mesin dan peralatan tersebut, selain memberikan kerugian bagi perusahaan dalam hal biaya demurrage, juga dapat menggangu jalannya proses produksi karena keterlambatan transportasi bahan baku juga bahkan dapat mengakibatkan terhentinya proses produksi. 
Akibatnya target produksi tidak tercapai dan beban biaya produksi semakin tinggi.

Selain kerugian dari sisi materiil seperti yang disebutkan di atas, kerusakan conveyor juga berpotensi menimbulkan masalah pada kesehatan para karyawan, karena menyebabkan area menjadi sangat berdebu. Hal ini menimbulkan unsafe condition karena cleaning tumpahan material bahan baku. Gangguangangguan terhadap mesin conveyor tersebut seringkali disebabkan karena waktu kapan terjadinya kegagalan tidak bisa diramalkan. Hal ini berkaitan dengan jenis perawatan mesin, belum adanya perencanaan jadwal perawatan berdasarkan analisis kegagalan mesin, dan tidak terencananya suku cadang penunjang sistem perawatan. Untuk mengatasi beberapa permasalahan tersebut, perlu dilakukan suatu analisis terhadap perawatan mesin dengan menggunakan metode Reliability Centered Maintenance (RCM).

PT Petrokimia Gresik selama ini belum pernah menerapkan metode tersebut dalam perawatan mesin di perusahaan. Oleh karenanya penelitian ini mencoba untuk mengusulkan sistem perawatan mesin dengan menggunakan metode Reliability Centered Maintenance (RCM). Metode RCM diharapkan dapat menetapkan schedule maintenance dan dapat mengetahui secara pasti tindakan kegiatan perawatan (maintenance task) yang tepat yang harus dilakukan pada setiap komponen mesin.

Tujuan dilakukannya penelitian ini adalah: (1) untuk mengetahui komponen yang sering mengalami kerusakan pada conveyor 02M603; (2) untuk mengetahui rata-rata waktu kerusakan dan rata-rata waktu perbaikan dari komponen kritis pada conveyor $02 \mathrm{M} 603$ sebagai dasar pembuatan keputusan model perawatan yang tepat; dan (3) untuk mengetahui tingkat keandalan dari komponen kritis pada conveyor 02M603.

\section{METODOLOGI}

Tahapan dalam penelitian ini terdiri dari:

1. Tahap Identifikasi dan Pendahuluan

Tahap ini merupakan tahap persiapan atas penelitian yang akan dilakukan. Tahapan ini terdiri dari: (a) Tahapan Studi Lapangan; (b) Tahapan Studi Literatur; (c) Perumusan Masalah; (d) Tujuan Penelitian

2. Tahap Pengumpulan Data

Data yang dikumpulkan terdiri dari: (a) data primer, yaitu jenis dan cara kerja conveyor 02M603, untuk memahami cara kerja komponen mesin, agar memudahkan menganalisa penyebab kerusakan pada conveyor 02M603; (b) data sekunder, yaitu data mengenai: data frekuensi dan waktu downtime dari kerusakan conveyor 02M603, data kerusakan komponen pada conveyor $02 \mathrm{M} 603$ dan data waktu perbaikan korektif komponen

Pengumpulan data dilakukan dengan cara: (a) observasi; (b) membaca buku-buku laporan administrasi serta catatan-catatan pihak perusahaan yang berhubungan dengan data yang diperlukan; (c) wawancara; (d) studi kepustakaan

3. Tahap Pengolahan Data

a. Penentuan Komponen Prioritas, sesuai langkah-langkah dari metode Reliability Centered Maintenance (RCM): (1) Pemilihan Sistem dan Pengumpulan Informasi; (2) Pendefinisian Batasan Sistem; (3) Penjelasan Sistem dan Blok Diagram Fungsi; (4) Fungsi Sistem dan Kegagalan Fungsi; (5) Analisis Mode Kegagalan dan Efek Kegagalan (FMEA); (6) Analisis Cabang Logika (LTA); (7) Pemilihan Tindakan;

b. Pengujian Pola Distribusi dan Reliability

Konsep keandalan terdiri atas empat bagian, yaitu Probability Density Function (PDF), Cumulative Distribution Function (CDF), Reliability Function, dan Hazard Function.

4. Tahap Analisis

Tahapan analisis data ini dilakukan dengan langkah-langkah sebagai berikut: (a) Merekomendasi tindakan perawatan hasil pendekatan RCM; (b) Rekomendasi Jadwal Pergantian Komponen; dan (c) Analisis Usulan Perawatan

5. Tahap Kesimpulan dan saran

Pada tahap kesimpulan dan saran, akan diberikan usulan perawatan komponen pada mesin conveyor $02 \mathrm{M} 603$ dan $02 \mathrm{M} 605$

Tahapan-tahapan dalam penelitian ini dapat digambarkan dalam diagram alir sebagai berikut: 


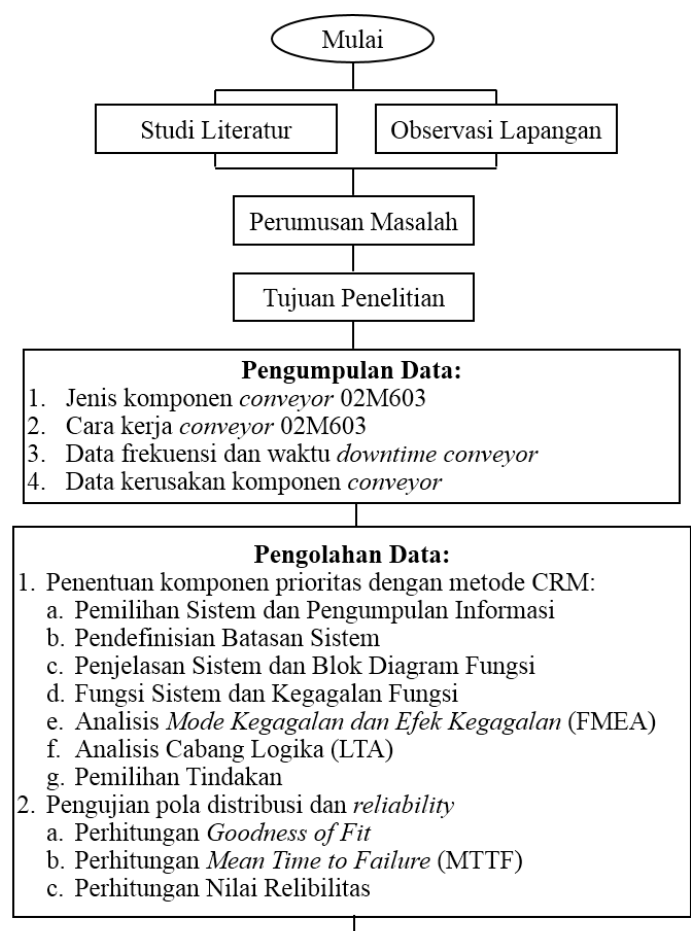

Analisis Data \& Pembahasan:

1. Merekomendasi tindakan perawatan hasil pendekatan RCM 2. Rekomendasi Jadwal Pergantian Komponen 3. Analisis Usulan Perawatan

$$
\begin{array}{|c|}
\hline \text { Kesimpulan \& Saran } \\
\text { Selesai }
\end{array}
$$

Gambar 1 Flowchart Penelitian

\section{HASIL DAN PEMBAHASAN}

\section{A. Data Kerusakan}

Tabel 1 Data Jenis dan Frekuensi Kerusakan Komponen Conveyor 02M603 Tahun 2018

\begin{tabular}{|c|c|c|c|c|}
\hline $\begin{array}{c}\text { Nama } \\
\text { Komponen }\end{array}$ & $\begin{array}{c}\text { Jenis } \\
\text { Kerusakan }\end{array}$ & $\begin{array}{c}\text { Tindakan Yang } \\
\text { Dilakukan }\end{array}$ & Frekuensi & $\begin{array}{c}\text { Downtime } \\
\text { (hoirs) }\end{array}$ \\
\hline Carrier Roller & Roller rusak & Ganti & 7 & 16,08 \\
\hline Support Carrier & Support patah & Ganti & 4 & 11,75 \\
\hline Rubber Seal & Rubber seal aus & Ganti & 4 & 8,25 \\
\hline Belt & Putus & Splicing & 4 & 12,50 \\
\hline Impact Roller & Roller rusak & Ganti & 3 & 8,75 \\
\hline \multicolumn{5}{|c|}{ Total } \\
\hline
\end{tabular}

Tabel 2 Data Hasil Perhitungan TTF dan TTR Carrier Roller

\begin{tabular}{|c|c|c|c|c|c|c|r|}
\hline \multirow{2}{*}{ No } & Tanggal & Tanggal & Waktu & Waktu Perbaikan & TTR & TTF \\
\cline { 5 - 8 } & Kerusakan & Perbaikan & Kerusakan & Mulai & Selesai & (jam) & (jam) \\
\hline 1 & $09 / 01 / 2018$ & $09 / 01 / 2018$ & 08.30 & 08.40 & 10.10 & 1,50 & 0,00 \\
\hline 2 & $12 / 03 / 2018$ & $12 / 03 / 2018$ & 10.25 & 10.40 & 13.15 & 1,58 & 183,08 \\
\hline 3 & $17 / 07 / 2018$ & $17 / 07 / 2018$ & 07.45 & 08.10 & 09.55 & 1,75 & 212,75 \\
\hline 4 & $13 / 08 / 2018$ & $13 / 08 / 2018$ & 09.00 & 09.25 & 10.55 & 1,50 & 189,08 \\
\hline 5 & $28 / 08 / 2018$ & $28 / 08 / 2018$ & 13.40 & 14.00 & 15.55 & 1,92 & 72,02 \\
\hline 6 & $25 / 10 / 2018$ & $25 / 10 / 2018$ & 10.30 & 10.45 & 14.10 & 2,42 & 127,58 \\
\hline 7 & $09 / 11 / 2018$ & $09 / 11 / 2018$ & 07.25 & 08.15 & 10.40 & 2,42 & 109,00 \\
\hline
\end{tabular}

Tabel 3 Data Hasil Perhitungan TTF dan TTR Support Carrier

\begin{tabular}{|c|c|c|c|c|c|c|c|}
\hline \multirow{2}{*}{ No } & \multirow{2}{*}{$\begin{array}{c}\text { Tanggal } \\
\text { Kerusakan }\end{array}$} & \multirow{2}{*}{$\begin{array}{c}\text { Tanggal } \\
\text { Perbaikan }\end{array}$} & \multirow{2}{*}{$\begin{array}{c}\text { Waktu } \\
\text { Kerusakan }\end{array}$} & \multicolumn{2}{|c|}{ Waktu Perbaikan } & \multirow{2}{*}{$\begin{array}{c}\text { TTR } \\
\text { (jam) }\end{array}$} & \multirow{2}{*}{$\begin{array}{r}\text { TTF } \\
\text { (jam) }\end{array}$} \\
\hline & & & & Mulai & Selesai & & \\
\hline 1 & $09 / 01 / 2018$ & $09 / 01 / 2018$ & 07.45 & 08.10 & 09.5 & 1,75 & 0,00 \\
\hline 2 & $17 / 07 / 2018$ & $17 / 07 / 2018$ & 08.00 & 08.15 & 11.25 & 3,17 & 316,25 \\
\hline 3 & $10 / 11 / 2018$ & $10 / 11 / 2018$ & 08.15 & 08.45 & 11.10 & 2,42 & 262,67 \\
\hline 4 & $21 / 12 / 2018$ & $21 / 12 / 2018$ & 11.20 & 13.00 & 16.35 & 2,58 & 156,83 \\
\hline
\end{tabular}

Tabel 4 Data Hasil Perhitungan TTF dan TTR Rubber Seal

\begin{tabular}{|c|c|c|c|c|c|c|r|}
\hline \multirow{2}{*}{ No } & Tanggal & Tanggal & \multirow{2}{*}{$\begin{array}{c}\text { Waktu } \\
\text { Kerusakan }\end{array}$} & \multicolumn{2}{|c|}{ Waktu Perbaikan } & TTR & TTF \\
\cline { 5 - 8 } & Perbaikan & Kerusakan & Mulai & Selesai & (jam) & (jam) \\
\hline 1 & $09 / 02 / 2018$ & $09 / 02 / 2018$ & 08.35 & 09.00 & 10.35 & 1,58 & 0,00 \\
\hline 2 & $05 / 06 / 2018$ & $05 / 06 / 2018$ & 14.00 & 14.30 & 16.00 & 1,50 & 312,75 \\
\hline 3 & $06 / 11 / 2018$ & $06 / 11 / 2018$ & 09.45 & 10.00 & 11.40 & 1,67 & 351,50 \\
\hline 4 & $06 / 12 / 2018$ & $06 / 12 / 2018$ & 10.00 & 10.15 & 13.20 & 2,08 & 173,33 \\
\hline
\end{tabular}

Tabel 5 Data Hasil Perhitungan TTF dan TTR Conveyor Belt

\begin{tabular}{|c|c|c|c|c|c|c|r|}
\hline \multirow{2}{*}{ No } & \multirow{2}{*}{$\begin{array}{c}\text { Tanggal } \\
\text { Kerusakan }\end{array}$} & Tanggal & \multirow{2}{*}{$\begin{array}{c}\text { Waktu } \\
\text { Perbaikan }\end{array}$} & \multicolumn{2}{|c|}{ Waktu Perbaikan } & \multirow{2}{*}{$\begin{array}{c}\text { TTR } \\
\text { Kerusakan }\end{array}$} & TTF \\
\cline { 5 - 8 } (jam) & Mulai & Selesai & \\
\hline 1 & $10 / 04 / 2018$ & $10 / 04 / 2018$ & 13.10 & 13.30 & 15.55 & 2,42 & 0,00 \\
\hline 2 & $13 / 08 / 2018$ & $13 / 08 / 2018$ & 08.00 & 08.30 & 11.45 & 3,25 & 923,92 \\
\hline 3 & $23 / 10 / 2018$ & $23 / 10 / 2018$ & 07.15 & 08.00 & 10.50 & 2,83 & 396,08 \\
\hline 4 & $06 / 12 / 2018$ & $06 / 12 / 2018$ & 09.00 & 09.25 & 11.25 & 2,00 & 255,67 \\
\hline
\end{tabular}

Tabel 6 Data Hasil Perhitungan TTF dan TTR Impact Roller

\begin{tabular}{|c|c|c|c|c|c|c|c|}
\hline \multirow{2}{*}{ No } & Tanggal & Tanggal & Waktu & \multicolumn{2}{|c|}{ Waktu Perbaikan } & TTR & TTF \\
\cline { 5 - 8 } & Kerusakan & Perbaikan & Kerusakan & Mulai & Selesai & (jam) & (jam) \\
\hline 1 & $22 / 04 / 2018$ & $22 / 04 / 2018$ & 08.20 & 08.30 & 11.15 & 2,75 & 0,00 \\
\hline 2 & $17 / 07 / 2018$ & $17 / 07 / 2018$ & 13.25 & 13.10 & 14.50 & 1,67 & 599,67 \\
\hline 3 & $21 / 11 / 2018$ & $21 / 11 / 2018$ & 07.35 & 07.45 & 11.30 & 3,75 & 718,17 \\
\hline
\end{tabular}

\section{B. Reliability Centered Maintenance (RCM) \\ 1. Pemilihan sistem dan pengumpulan informasi}

Berdasarkan wawancara dan data dokumentasi perusahaan dari Bagian Prasarana dan Utilitas Departemen Pengelolaan Pelabuhan PT Petrokimia Gresik, kegagalan pada komponen paling banyak terjadi pada salah satu mesin yaitu mesin conveyor $02 \mathrm{M} 603$ sehingga pengumpulan informasi dilakukan pada mesin conveyor 02M603. Proses analisis RCM sebaiknya dilakukan pada tingkat sistem bukan pada tingkat komponen. Namun proses analisis dilakukan pada sistem permesinan mesin conveyor 02M603 karena memiliki downtime paling tinggi yaitu 57,33 jam dengan jam operasi 2985 jam/tahun.

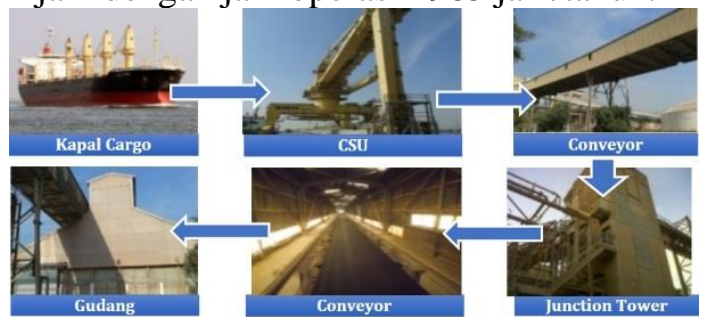

Gambar 2 Proses Unloading Phosphate Rock di Pelabuhan Petrokimia Gresik

\section{Pendefinisian batasan sistem}

Definisi batasan sistem pada metode Reliability Centered Maintenance biasanya dibuat dalam bentuk formulir deskriptif dari sistem itu sendiri seperti yang diperlihatkan pada Formulir RCM-System Analysis.

Tabel 7 Definisi Batasan Sistem Conveyor $02 \mathrm{M} 603$ 


\begin{tabular}{lll}
\hline OUT & Eject & $\begin{array}{l}\text { Material sebelumnya melalui CSU, conveyor 02M602 dan } \\
\text { juction tower }\end{array}$ \\
\hline IN & Injection & Material kemudian dibawa menuju gudang F1 \\
\hline OUT & Eject & $\begin{array}{l}\text { Conveyor 02M603 memiliki lintasan kombinasi inklinasi } \\
\text { dan horizontal }\end{array}$ \\
\hline OUT & Eject & $\begin{array}{l}\text { Panjang lintasan conveyor 02M603 adalah sepanjang 1 } \\
\text { kilometer dari juction tower hingga gudang }\end{array}$ \\
\hline OUT & Eject & $\begin{array}{l}\text { Material yang ditransport kapasitasnya lebih dari 2000 } \\
\text { ton/jam }\end{array}$ \\
\hline & &
\end{tabular}

\section{Deskripsi sistem dan blok fungsi}

Ada beberapa item yang dikembangkan pada tahap ini yaitu:

a. Deskripsi sistem (system description)

1) Unit Utama:

Belt, yang berfungsi sebagai alas dari material yang diangkut.

2) Unit Pendukung:

a) Carrier roller berfungsi sebagai pengantar belt beserta material yang ditransfer serta menahan belt agar tidak mengalami lendutan yang dapat menimbulkan kebocoran pada celah.

b) Support carrier merupakan tumpuan pemasangan carrier roller

c) Impact roller berfungsi sebagai penahan jatuhan material dan melindungi belt dari benturan material terhadap carrier roller

3) Unit Tambahan:

Rubber seal, yang berfungsi sebagai alas dari material yang diangkut.

b. Blok Diagram Fungsi

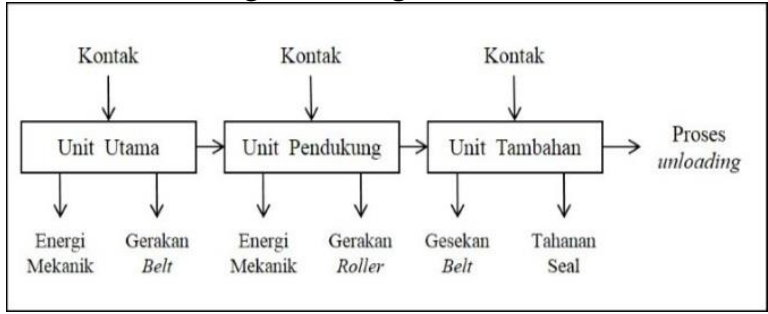

Gambar 3 Blok Diagram Fungsi Mesin

Conveyor $02 \mathrm{M} 603$

c. System Work Breakdown Structure (SWBS)

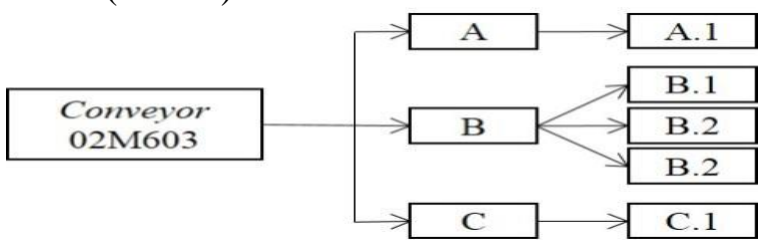

Gambar 4 System Work Breakdown Structure (SWBS)

Uraian pengkodean SWBS:

Tabel 8 SWBS Conveyor 02M603

\begin{tabular}{|c|c|c|c|}
\hline \multirow{2}{*}{ Kode } & Unit & Kode & $\begin{array}{c}\text { Nama } \\
\text { Komponen }\end{array}$ \\
\hline A & Unit Utama & A.1 & Belt \\
\hline \multirow{2}{*}{ B } & \multirow{2}{*}{ Unit Pendukung } & B.1 & Carrier Roller \\
\cline { 3 - 4 } & & B.2 & Support Carrier \\
\cline { 3 - 4 } & B.3 & Impact Roller \\
\hline C & Unit Tambahan & C.1 & Rubber Seal \\
\hline
\end{tabular}

d. Data historis equipment

Tabel 9 Data Historis Peralatan

\begin{tabular}{|c|c|c|c|}
\hline No. & Part & Failure Mode & Failure Cause \\
\hline 1 & Belt & Belt putus & $\begin{array}{l}\text { 1. Gesekan dengan } \\
\text { scrapper yang terlalu } \\
\text { menekan } \\
\text { 2. Kesalahan } \\
\text { splicing } \\
\text { 3. Overload }\end{array}$ \\
\hline 2 & $\begin{array}{c}\text { Carrier } \\
\text { Roller }\end{array}$ & Roller rusak & $\begin{array}{l}\text { 1. Pemasangan tidak } \\
\text { allignment } \\
\text { 2. Rubber lining aus } \\
\text { 3. Bearing rusak }\end{array}$ \\
\hline 3 & $\begin{array}{l}\text { Support } \\
\text { Carrier }\end{array}$ & Support patah & $\begin{array}{l}\text { 1. Pemasangan tidak } \\
\text { allignment } \\
\text { 2. Screw patah } \\
\text { 3. Korosi }\end{array}$ \\
\hline 4 & Impact Roller & Roller rusak & $\begin{array}{l}\text { 1. Pemas angan tidak } \\
\text { allignment } \\
\text { 2. Rubber lining aus } \\
\text { 3. Bearing rusak }\end{array}$ \\
\hline 5 & Rubber Seal & Seal aus & $\begin{array}{l}\text { 1. Belt miring sehingga } \\
\text { menggerus seal di satu } \\
\text { titik } \\
\text { 2. Pemasangan terlalu } \\
\text { rapat sehingga gesekan } \\
\text { dengan belt makin } \\
\text { besar }\end{array}$ \\
\hline
\end{tabular}

4. Pendeskripsian fungsi sistem dan kegagalan fungsi

Pengkodean fungsi dan kegagalan fungsi dilakukan dengan keterangan sebagai berikut:

a. Huruf melambangkan nama unit operasi dari mesin conveyor $02 \mathrm{M} 603$.

b. Angka pertama melambangkan nama komponen utama dari mesin conveyor $02 \mathrm{M} 603$

c. Angka kedua melambangkan kegagalan fungsi.

Tabel 10 Fungsi Sistem dan Kegagalan Fungsi

\begin{tabular}{|c|c|c|}
\hline $\begin{array}{l}\text { Kode Fungsi } \\
\text { Sistem }\end{array}$ & $\begin{array}{c}\text { Kode } \\
\text { Kegagalan } \\
\text { Fungsi }\end{array}$ & Uraian \\
\hline \multirow[t]{2}{*}{ A.1 } & & $\begin{array}{l}\text { Berfungsi sebagai alas material yang } \\
\text { diangkut }\end{array}$ \\
\hline & A.1.1 & $\begin{array}{l}\text { Mengalami kerusakan akibat adanya } \\
\text { gesekan dengan scrapper yang terlalu } \\
\text { menekan, kesalahan pada splicing dan } \\
\text { overload }\end{array}$ \\
\hline \multirow[t]{2}{*}{ B. 1} & & $\begin{array}{l}\text { Berfungsi sebagai pengantar belt } \\
\text { beserta material yang ditransfer serta } \\
\text { menahan belt agar tidak mengalami } \\
\text { lendutan yang dapat menimbulkan } \\
\text { kebocoran pada celah }\end{array}$ \\
\hline & B.1.1 & $\begin{array}{l}\text { Mengalami kerusakan akibat } \\
\text { pemasangan tidak allignment, rubber } \\
\text { lining yang aus dan bearing yang rusak }\end{array}$ \\
\hline B. 2 & B2.1 & $\begin{array}{l}\text { Berfungsi sebagai tumpuan } \\
\text { pemasangan carrier roller } \\
\text { Mengalami kerusakan akibat } \\
\text { pemasangan tidak allignment, screw } \\
\text { patah dan korosi }\end{array}$ \\
\hline \multirow[t]{2}{*}{ B. 3} & & $\begin{array}{l}\text { Berfungsi sebagai penahan jatuhan } \\
\text { material dan melindungi belt dari } \\
\text { benturan material terhadap carrier } \\
\text { roller }\end{array}$ \\
\hline & B. 3.1 & $\begin{array}{l}\text { Mengalami kerusakan akibat } \\
\text { pemasangan tidak allignment, rubber } \\
\text { lining yang aus dan bearing yang rusak }\end{array}$ \\
\hline \multirow[t]{2}{*}{ C. 1} & & $\begin{array}{l}\text { Berfungsi sebagai penyekat agar } \\
\text { material tidak keluar dani belt pada saat } \\
\text { proses transfer }\end{array}$ \\
\hline & C.1.1 & $\begin{array}{l}\text { Mengalami kerusakan karena posisi } \\
\text { belt mring sehingga menggerus seal di } \\
\text { satu titik dan karena pemasangan terlalu } \\
\text { rapat sehingga gesekan dengan belt } \\
\text { menjadi semakin besar }\end{array}$ \\
\hline
\end{tabular}




\section{Penyusunan Failure Mode and Effect Analysis (FMEA)}

Tabel 11 Fungsi Sistem dan Kegagalan Fungsi

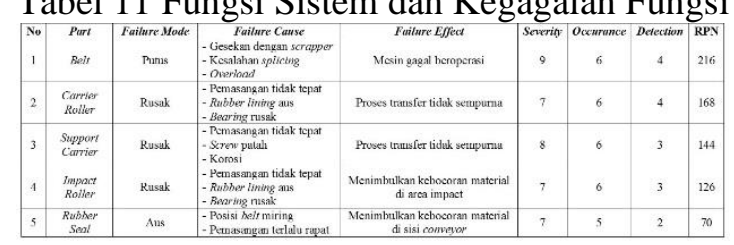

Pada hasil FMEA peralatan yang memiliki RPN tertinggi akan diprioritaskan dalam kegiatan perawatan. Urutan komponen yang memiliki RPN tertinggi sampai yang terendah adalah belt conveyor, carrier roller, support carrier, impact roller, dan rubber seal.

\section{Penyusunan Logic Tree Analysis (LTA)}

LTA (Logic Tree Analysis) untuk komponen yang menyebabkan kegagalan fungsi sistem pengangkutan material phosphate rock adalah sebagai berikut:

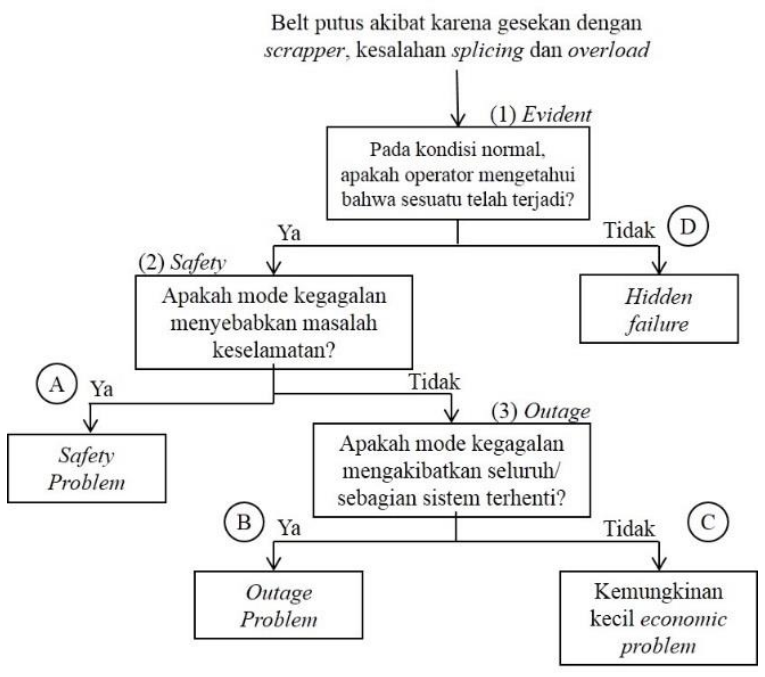

Gambar 4 Penyusunan LTA

Rekapitulasi Logic Tree Analysis pada mesin conveyor 02M603:

Tabel 12 Fungsi Sistem dan Kegagalan Fungsi

\begin{tabular}{|c|c|c|c|c|c|c|}
\hline No. & Part & Failure Mode & Evident & Safety & Outage & Category \\
\hline 1 & Belt & Putus & Y & T & Y & B \\
\hline 2 & Carrier Roller & Rusak & Y & T & Y & B \\
\hline 3 & Support Carrier & Rusak & Y & T & Y & B \\
\hline 4 & Impact Roller & Rusak & Y & T & T & C \\
\hline 5 & Rubber Seal & Aus & Y & T & T & C \\
\hline
\end{tabular}

\section{Pemilihan Tindakan}

Tabel 13 Pemilihan Tindakan Perawatan Mesin Conveyor 02M603

\begin{tabular}{|c|c|c|c|c|c|c|c|c|c|}
\hline \multirow{2}{*}{ No. } & \multirow{2}{*}{ Part } & \multirow{2}{*}{$\begin{array}{c}\text { Failure } \\
\text { Mode }\end{array}$} & \multicolumn{6}{|c|}{ Selection Guide } & Selection \\
\cline { 4 - 9 } & & & $\mathbf{1}$ & $\mathbf{2}$ & $\mathbf{3}$ & $\mathbf{4}$ & $\mathbf{5}$ & $\mathbf{6}$ & \\
\hline 1 & Belt & Putus & Y & Y & T & T & - & Y & C.D. \\
\hline 2 & Carrier Roller & Rusak & Y & Y & T & T & - & Y & T.D. \\
\hline 3 & Support Carrier & Rusak & Y & Y & T & T & & Y & T.D. \\
\hline 4 & Impact Roller & Rusak & Y & Y & T & T & & Y & T.D. \\
\hline 5 & Rubber Seal & Aus & Y & T & T & T & & Y & T.D. \\
\hline
\end{tabular}

Pemilihan tindakan pencegahan berdasarkan hasil analisis terhadap FMEA dan LTA adalah sebagai berikut: a. Time Directed (T.D) yaitu tindakan yang diambil yang lebih berfokus pada aktivitas pergantian yang dilakukan secara berkala. Komponen yang termasuk dalam pemilihan tindakan ini adalah:
1) Carrier Roller
2) Support Carrier
3) Impact Roller
4) Rubber Seal

b. Condition Directed (C.D), tindakan yang diambil yang bertujuan untuk mendeteksi kerusakan dengan cara visual inspection, memeriksa alat, serta memonitoring sejumlah data yang ada. Komponen yang termasuk dalam pemilihan tindakan ini adalah Conveyor Belt.

\section{Pengujian Pola Distribusi dan Reliability}

Berdasarkan hasil analisis RCM pada komponen mesin conveyor 02M603, maka komponen yang akan diuji pola distribusinya dan kemudian ditentukan nilai reliability-nya adalah komponen yang tindakan perawatannya bersifat waktu/Time Directed (TD). Komponen tersebut adalah carrier roller, support carrier, impact roller dan rubber seal. Namun karena data TTF dari impact roller hanya 2, maka tidak dapat dilakukan perhitungan ditribusi serta MTTF. Dengan demikian perhitungan lebih lanjut hanya dilakukan pada carrier roller, support carrier dan rubber seal.

\section{Komponen Carrier Roller}

Tabel 14 Hasil Perhitungan Goodness of Fit

$$
\text { Carrier Roller }
$$

\begin{tabular}{|c|c|c|c|c|}
\hline \multirow{2}{*}{ Distribusi } & \multicolumn{2}{|c|}{ TTF } & \multicolumn{2}{c|}{ TTR } \\
\cline { 2 - 5 } & $\begin{array}{c}\text { Anderson- } \\
\text { Darling }\end{array}$ & $\begin{array}{c}\text { Correlation } \\
\text { Coefficient }\end{array}$ & $\begin{array}{c}\text { Anderson- } \\
\text { Darling }\end{array}$ & $\begin{array}{c}\text { Correlation } \\
\text { Coefficient }\end{array}$ \\
\hline Weibull & 2,060 & 0,984 & 2,420 & 0,902 \\
\hline Normal & 2,069 & 0,976 & 2,041 & 0,927 \\
\hline Lognormal & 2,132 & 0,962 & 1,970 & 0,939 \\
\hline Exponential & 3,565 & $*$ & 4,631 & $*$ \\
\hline
\end{tabular}

Tabel 15 Hasil Perhitungan MTTF Carrier Roller Distribusi Weibull

\begin{tabular}{|c|c|c|c|c|c|}
\hline \multirow{2}{*}{ MTTF } & Std. & \multicolumn{2}{|c|}{$\mathbf{9 5 \%}$ Normal CI } & \multirow{2}{*}{$\boldsymbol{\beta}$} & \multirow{2}{*}{$\boldsymbol{\theta}$} \\
\cline { 3 - 4 } & Error & Lower & Upper & & \\
\hline 150,113 & 25,1166 & 108,143 & 208,373 & 2,6129 & 168,982 \\
\hline
\end{tabular}

Karena distribusi yang terpilih adalah Weibull, maka hasil MTTF carrier roller adalah 150,113 jam dan pada CI 95\% maka umur pemakaian carrier roller adalah antara 108,143 hingga 208,373 jam.

Tabel 16 Hasil Perhitungan MTTR Carrier Roller Distribusi Lognormal

\begin{tabular}{|c|c|c|c|}
\hline \multirow{2}{*}{ Mean } & \multirow{2}{*}{ Std. Error } & \multicolumn{2}{|c|}{ 95\% Normal CI } \\
\cline { 3 - 4 } & & Lower & Upper \\
\hline 1,87832 & 0,15795 & 1,59291 & 2,21488 \\
\hline
\end{tabular}

Karena distribusi yang terpilih adalah Lognormal, maka hasil MTTR carrier roller 
adalah 1,89 jam dan pada CI 95\% maka waktu perbaikan carrier roller adalah antara 1,593 hingga 2,215 jam.

Selanjutnya berdasarkan hasil simulasi perhitungan reliabilitas carrier roller dapat dijelaskan bahwa:

a. Dengan jadwal perawatan awal yaitu tiap 200 jam (Ta), dapat diketahui tingkat keandalan yaitu $18,13 \%$ saat dilakukan perawataan.

b. Dengan usulan perawatan tiap 100 jam sekali $\left(\mathrm{T}^{*}\right)$, maka tingkat keandalan $73,79 \%$ saat dilakukan perawatan.

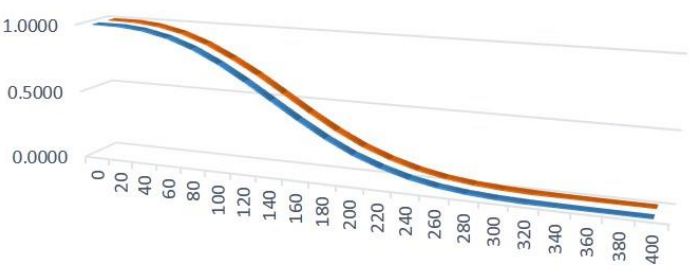

ఐ Waktu Perawatan Tiap 200 jam Usulan Waktu Perawatan Tiap 100 jam

Gambar 5 Peningkatan Reliabilitas Carrier

$$
\text { Roller }
$$

\section{Komponen Support Carrier}

Tabel 17 Hasil Perhitungan Goodness of Fit Support Carrier

\begin{tabular}{|c|c|c|c|c|}
\hline \multirow{2}{*}{ Distribusi } & \multicolumn{2}{|c|}{ TTF } & \multicolumn{2}{c|}{ TTR } \\
\cline { 2 - 5 } & $\begin{array}{c}\text { Anderson- } \\
\text { Darling }\end{array}$ & $\begin{array}{c}\text { Correlation } \\
\text { Coefficient }\end{array}$ & $\begin{array}{c}\text { Anderson- } \\
\text { Darling }\end{array}$ & $\begin{array}{c}\text { Correlation } \\
\text { Coefficient }\end{array}$ \\
\hline Weibull & 3,474 & 0,983 & 2,795 & 0,986 \\
\hline Normal & 3,479 & 0,983 & 2,799 & 0,986 \\
\hline Lognormal & 3,511 & 0,965 & 2,826 & 0,976 \\
\hline Exponential & 4,035 & $*$ & 3,991 & $*$ \\
\hline
\end{tabular}

Tabel 18 Hasil Perhitungan MTTF Support

Carrier Distribusi Weibull

\begin{tabular}{|c|c|c|c|c|c|}
\hline \multirow{2}{*}{ MTTF } & Std. & \multicolumn{2}{|c|}{$95 \%$ Normal CI } & \multirow{2}{*}{$\boldsymbol{B}$} & $\boldsymbol{\theta}$ \\
\cline { 3 - 4 } & Error & Lower & Upper & & \\
\hline 247,965 & 61,094 & 152,992 & 401,893 & 2,70283 & 278,827 \\
\hline
\end{tabular}

Karena distribusi yang terpilih adalah Weibull, maka hasil MTTF support carrier adalah 247,97 jam dan pada CI 95\% maka umur pemakaian support carrier adalah antara 152,99 hingga 401,89 jam.

Tabel 19 Hasil Perhitungan MTTR Support Carrier Distribusi Weibull

\begin{tabular}{|c|c|c|c|}
\hline \multirow{2}{*}{ Mean } & \multirow{2}{*}{ Std. Error } & \multicolumn{2}{|c|}{ 95\% Normal CI } \\
\cline { 3 - 4 } & & Lower & Upper \\
\hline 2,47162 & 0,33065 & 1,90155 & 3,21259 \\
\hline
\end{tabular}

Karena distribusi yang terpilih adalah Weibull, maka hasil MTTR support carrier adalah 2,47 jam dan pada CI 95\% maka waktu perbaikan support carrier adalah antara 1,902 hingga 3,213 jam.

Selanjutnya berdasarkan hasil simulasi perhitungan reliabilitas support carrier dapat dijelaskan bahwa: a. Dengan jadwal perawatan awal yaitu tiap 200 jam (Ta), dapat diketahui tingkat keandalan yaitu $51,72 \%$ saat dilakukan perawataan.

b. Dengan usulan perawatan tiap 100 jam sekali ( $\left.\mathrm{T}^{*}\right)$, maka tingkat keandalan $90,47 \%$ saat dilakukan perawatan.

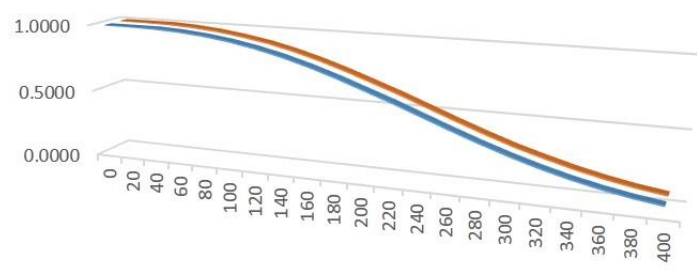

Waktu Perawatan Tiap 200 jam = Usulan Perawatan Tiap 100 jam

Gambar 6 Peningkatan Reliabilitas Support Carrier

\section{Komponen Rubber Seal}

Tabel 20 Hasil Perhitungan Goodness of Fit Rubber Seal

\begin{tabular}{|c|c|c|c|c|}
\hline \multirow{2}{*}{ Distribusi } & \multicolumn{2}{|c|}{ TTF } & \multicolumn{2}{c|}{ TTR } \\
\cline { 2 - 5 } & $\begin{array}{c}\text { Anderson- } \\
\text { Darling }\end{array}$ & $\begin{array}{c}\text { Correlation } \\
\text { Coefficient }\end{array}$ & $\begin{array}{c}\text { Anderson- } \\
\text { Darling }\end{array}$ & $\begin{array}{c}\text { Correlation } \\
\text { Coefficient }\end{array}$ \\
\hline Weibull & 3,526 & 0,959 & 3,197 & 0,892 \\
\hline Normal & 3,537 & 0,951 & 2,918 & 0,919 \\
\hline Lognormal & 3,571 & 0,933 & 2,884 & 0,933 \\
\hline Exponential & 4,065 & $*$ & 4,235 & $*$ \\
\hline
\end{tabular}

Tabel 21 Hasil Perhitungan MTTF Rubber Seal Distribusi Weibull

\begin{tabular}{|c|c|c|c|c|c|}
\hline \multirow{2}{*}{ MTTF } & Std. & \multicolumn{2}{|c|}{$95 \%$ Normal CI } & \multirow{2}{*}{$\boldsymbol{\beta}$} & \multirow{2}{*}{$\boldsymbol{\theta}$} \\
\cline { 3 - 4 } & Error & Lower & Upper & & \\
\hline 282,143 & 73,0992 & 169,799 & 468,817 & 2,65649 & 317,442 \\
\hline
\end{tabular}

Karena distribusi yang terpilih adalah Weibull, maka hasil MTTF rubber seal adalah 282,14 jam dan pada CI 95\% maka umur pemakaian rubber seal adalah antara 169,80 hingga 468,82 jam.

Tabel 22 Hasil Perhitungan MTTR Rubber Seal Distribusi Lognormal

\begin{tabular}{|c|c|c|c|}
\hline \multirow{2}{*}{ Mean } & \multirow{2}{*}{ Std. Error } & \multicolumn{2}{|c|}{ 95\% Normal CI } \\
\cline { 3 - 4 } & & Lower & Upper \\
\hline 1,71608 & 0,13815 & 1,46559 & 2,00938 \\
\hline
\end{tabular}

Karena distribusi yang terpilih adalah Lognormal, maka hasil MTTR rubber seal adalah 1,72 jam dan pada CI 95\% maka waktu perbaikan rubber seal adalah antara 1,466 hingga 2,009 jam.

Selanjutnya berdasarkan hasil simulasi perhitungan reliabilitas rubber seal dapat dijelaskan bahwa:

a. Dengan jadwal perawatan awal yaitu tiap 200 jam (Ta), dapat diketahui tingkat keandalan yaitu $68,87 \%$ saat dilakukan perawatan. 
b. Dengan usulan perawatan tiap 100 jam sekali ( $\left.\mathrm{T}^{*}\right)$, maka tingkat keandalan $92,89 \%$ saat dilakukan perawatan

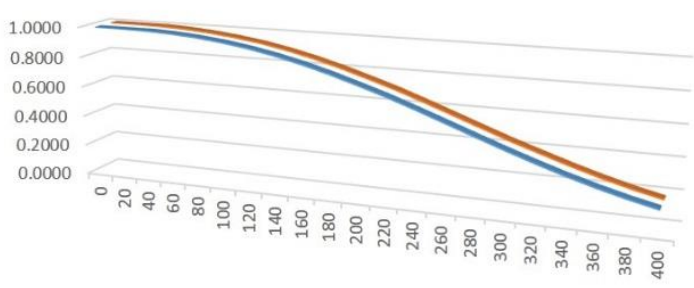

= Waktu Perawatan Tiap 200 jam = Usulan Waktu Perawatan Tiap 100 jam

Gambar 7 Peningkatan Reliabilitas rubber seal

\section{ANALISIS}

\section{Analisis Jenis Kerusakan}

Selama tahun 2018 , conveyor $02 \mathrm{M} 603$ mengalami kerusakan sebanyak 22 kali dengan downtime selama 56,58 jam (3395 menit). Kerusakan pada conveyor 02M603 tidak selalu terjadi pada setiap bulan, dengan frekuensi yang bervariasi pula. Frekuensi kerusakan conveyor $02 \mathrm{M} 603$ terbanyak terjadi pada bulan November 2018, yaitu sebanyak 4 kali dengan downtime selama 12,17 jam (730 menit). Adapun jenis kerusakan yang terjadi antara lain:

a. Belt putus akibat adanya gesekan dengan scrapper yang terlalu menekan, kesalahan pada splicing dan overload

b. Carrier roller rusak akibat pemasangan tidak allignment, rubber lining yang aus dan bearing yang rusak

c. Support carrier rusak akibat pemasangan tidak allignment, screw patah dan korosi

d. Impact roller rusak akibat pemasangan tidak allignment, rubber lining yang aus dan bearing yang rusak

e. Rubber seal aus karena posisi belt miring sehingga menggerus seal di satu titik dan karena pemasangan terlalu rapat sehingga gesekan dengan belt menjadi semakin besar

\section{Analisis Komponen Kritis Mesin}

Komponen kritis conveyor 02M603 sesuai dengan data yang diperoleh adalah belt, carrier roller, support carrier, impact roller dan rubber seal. Berdasarkan pemilihan tindakan yang dilakukan pada reliability centered maintenance, komponen yang akan dihitung reliability adalah komponen termasuk pada kategori time directed. Dengan demikian pengujian reliability hanya dilakukan pada komponen carrier roller, support carrier, impact roller dan rubber seal. Dari perhitungan reliabilitas untuk ketiga komponen conveyor 02M603 tersebut diperoleh hasil sebagai berikut:

a. Carrier Roller $=48,00 \%$

b. Support Carrier $=48,27 \%$

c. Rubber seal $=48,14 \%$

Berdasarkan hasil tersebut dapat dilihat bahwa tingkat keandalan tiga komponen dengan kerusakan terbanyak dari conveyor 02M603 tersebut masih sangat rendah, yaitu di bawah 50\%. Kondisi ini tentu akan sangat merugikan bagi perusahaan karena kerusakan yang terjadi akan dapat menghentikan proses bongkar phosphate rock yang dilakukan dan menimbulkan biaya demurrage yang cukup besar.

\section{Analisis Usulan Perawatan}

Perawatan komponen selama ini dilakukan dalam waktu 200 jam atau 2 kali waktu bongkar. Dengan jadwal perawatan ini, khususnya untuk carrier roller, yang MTTF-nya sebesar 150,113, maka bisa jadi komponen tersebut sudah mengalami kerusakan yang mengakibatkan downtime. Oleh karenanya diusulkan untuk melakukan penjadwalan perawatan setiap 100 jam agar keandalan dari komponen dapat ditingkatkan. Hal ini dapat dibuktikan dari hasil simulasi yang menunjukkan bahwa:

\section{a. Carrier roller}

1) Dengan jadwal perawatan awal yaitu tiap 200 jam, dapat diketahui tingkat keandalan yaitu $18,13 \%$ saat dilakukan perawatan.

2) Dengan usulan perawatan tiap 100 jam sekali, maka tingkat keandalan $73,79 \%$ saat dilakukan perawatan.

b. Support carrier

1) Dengan jadwal perawatan awal yaitu tiap 200 jam, dapat diketahui tingkat keandalan yaitu $51,72 \%$ saat dilakukan perawataan.

2) Dengan usulan perawatan tiap $100 \mathrm{jam}$ sekali, maka tingkat keandalan $90,47 \%$ saat dilakukan perawatan.

\section{c. Rubber Seal}

1) Dengan jadwal perawatan awal yaitu tiap 200 jam, dapat diketahui tingkat keandalan yaitu $\quad 68,87 \%$ saat dilakukan perawataan. 
2) Dengan usulan perawatan tiap 100 jam sekali, maka tingkat keandalan $92,89 \%$ saat dilakukan perawatan Berdasarkan hasil tersebut, jadwal perawatan komponen yang selama ini dilakukan dalam waktu 200 jam atau 2 kali waktu bongkar masih berjalan cukup baik untuk komponen support carrier dan rubber seal. Namun karena perawatan yang biasa dilakukan juga dilakukan secara menyeluruh pada semua komponen, maka usulan perawatan yang disarankan adalah dilakukan tiap 100 jam atau setiap 1 kali bongkar phosphate rock, sehingga akan dapat meminimalkan terjadinya downtime pada conveyor $02 \mathrm{M} 603$.

\section{KESIMPULAN}

1. Komponen kritis yang menjadi prioritas pada conveyor 02M603 di PT. Petrokimia Gresik adalah carrier roller, support carrier dan rubber seal, yang sering mengalami kerusakan pada tahun 2018. Oleh karenanya, demi kelancaran proses bongkar phosphate rock di pelabuhan PT Petrokimia Gresik, serta meminimalkan biaya demurrage yang timbul, maka ketiga komponen tersebut memerlukan penggantian dalam periode waktu tertentu.

2. Rata-rata waktu kerusakan untuk komponen carrier roller adalah 150,11 jam, komponen support carrier adalah 247,97 jam dan komponen rubber seal adalah 282,14 jam. Rata-rata waktu perbaikan untuk komponen carrier roller adalah 1,88 jam, komponen support carrier adalah 2,47 jam dan komponen rubber seal adalah 1,72 jam.

3. Persentase keandalan dari komponen carrier roller adalah 48\%, komponen support carrier adalah 48,27\% dan komponen rubber seal adalah $48,14 \%$. Tingkat keandalan tiga komponen dengan kerusakan terbanyak dari conveyor 02M603 tersebut masih sangat rendah, yaitu di bawah 50\%. Dengan usulan perawatan tiap 100 jam sekali, maka tingkat keandalan saat dilakukan perawatan komponen carrier roller meningkat menjadi $73,79 \%$, komponen support carrier meningkat menjadi 90,47\% dan komponen rubber seal meningkat menjadi $92,89 \%$.

\section{DAFTAR PUSTAKA}

Algifari. 2010. Analisis Regresi, Teori, Kasus dan Solusi. Edisi Kedua. Yogyakarta: BPFE

Anggraini, W. dan Risvaldi. (2016). Preventive Maintenance Pada Komponen Kritis Mesin Dengan Metode Reliability Centered Maintenance. Seminar Nasional IENACO. Hal. 292-300

Ansori, N dan M.I. Mustajib. (2013). Sistem Perawatan Terpadu. Yogyakarta: Graha Ilmu.

Asisco, H.; K. Amar dan Y.R. Perdana. (2012). Usulan Perencanaan Perawatan Mesin dengan Metode Reliability Centered Maintenance (RCM) di PT. Perkebunan Nusantara VII (Persero) Unit Usaha Sungai Niru Kab. Muara Enim. Kaunia. Vol. VIII, No. 2. Hal. 78-98.

Birolini, A. (2003) Reliability Engineering. Tuscany, Italy: Springer.

Ebeling, C.E., (1997), An Introduction To Reliability and MaintaibilityEngineer. Singapore: Mc. Graw-Hill Book Co.

Gaspersz, V. (2002). Total Quality Management. Jakarta: Gramedika Pustaka Utama.

Hartini, S. dan Sriyanto. (2006). Pemetaan Perawatan Untuk Meminimasi Breakdown Dengan Pendekatan Reliability Centered Maintenance. Transistor, Vol.8, No. 2. Hal. 11-19

Jardine, A.K.S. (1973), Maintenance, Replacement and Reliability, Department of Engineering Production Universitas of Birmingham.

Kurniawan, F. (2013) Manajemen Perawatan Industri.: Yogyakarta: Graha Ilmu

Manzini, R. (2010) Maintenance for Industrial System. London: Springer.

Moubray, J. 1997. Reliability Centered Maintenance. New York: Industrial Press Inc 